\title{
Meningiomas and cyproterone acetate: a retrospective, monocentric cohort of 388 patients treated by surgery or radiotherapy for intracranial meningioma
}

\author{
Edouard Samarut ${ }^{1} \cdot$ Alexandre Lugat $^{2,3}$ (1) $\cdot$ Aymeric Amelot $^{4,5} \cdot$ Emeric Scharbarg $^{2} \cdot$ Samy Hadjadj $^{2} \cdot$ Claire Primot $^{6}$. \\ Delphine Loussouarn ${ }^{7} \cdot$ François Thillays $^{8} \cdot$ Kevin Buffenoir $^{1} \cdot$ Bertrand Cariou $^{2} \cdot$ Delphine Drui $^{2} \cdot$ Vincent Roualdes $^{1}$
}

Received: 14 November 2020 / Revised: 15 December 2020 / Accepted: 16 December 2020 / Published online: 3 January 2021

(C) The Author(s), under exclusive licence to Springer Science+Business Media, LLC part of Springer Nature 2021

\begin{abstract}
Purpose Meningiomas are the most common intracranial tumors, accounting for 20-30\% of central nervous system tumors. Recently, the European Medicines Agency issued an alert on cyproterone acetate (CPA) based on the results of a study that found an increased risk of meningioma 7 to 20 times higher when a patient is on CPA.

The primary objective of this study was to determine the prevalence of CPA exposure in patients who had one or more intracranial meningiomas treated surgically or with radiation therapy. The secondary objectives were to establish a description of the patients who had intracranial meningioma in Nantes and to establish whether there was a difference in the intrinsic and tumoral characteristics of patients exposed to CPA compared with patients who had no hormonal exposure and patients who had been exposed to other hormones.

Methods Monocentric, retrospective study including all patients treated by surgery or radiotherapy for intracranial meningioma from 2014 to 2017 excluding those with a history of exposure to ionizing radiation or neurofibromatosis type 2 .

Results 388 patients were included, 277 were treated by surgery and 111 by radiotherapy. $3.9 \%$ of the patients had a history or current use of CPA, $16.2 \%$ were taking other hormonal treatment. Compared with the group without hormonal exposure, the CPA-exposed group had significantly an earlier onset of meningiomas at 48.9 vs. 61.9 years $(\mathrm{p}=0.0005)$ and had more multiple meningiomas, $26.7 \%$ vs. $6.1 \%(\mathrm{p}=0.0115)$.

Conclusions In our study, patients with a history or current use of CPA had significantly more meningiomas and were significantly younger at the onset.
\end{abstract}

Keywords Meningioma $\cdot$ Cyproterone acetate $\cdot$ Progestative $\cdot$ Hirsutism $\cdot$ Polycystic ovary syndrome

Supplementary Information The online version contains supplementary material available at https://doi.org/10.1007/s1106 0-020-03683-6.

Edouard Samarut and Alexandre Lugat have equally contributed to this manuscript.

Delphine Drui and Vincent Roualdes have equally contributed to this manuscript.

Delphine Drui

delphine.drui@chu-nantes.fr

Vincent Roualdes

vincent.roualdes@chu-nantes.fr

Extended author information available on the last page of the article

\section{Introduction}

Meningiomas are intracranial, extra-parenchymal tumors developed from non-neuroepithelial cells: arachnoid cells [1]. They are the most common intracranial tumors (20-30\%) [2-4].

Most meningiomas are benign, developing slowly with a long asymptomatic period. They may be revealed incidentally by brain imaging or neurological symptoms such as a seizure, focal sensory-motor deficit or headache [5].

Currently, two risk factors for meningioma have been identified: exposure to ionizing radiation, whether therapeutic [6] or accidental [7], and certain genetic predisposition syndromes such as neurofibromatosis type 2 (NF2) [8]. 
The prevalence of meningiomas varies from 50.4 to $70 / 100,000$ and the incidence in women is two to three times higher than in men [9]. Given this female predominance and the discovery of the expression of progesterone receptors by meningiomas as early as 1993 [10], the influence of exposure to hormonal treatments, particularly cyproterone acetate (CPA), has been investigated.

CPA is an anti-androgenic drug derived from hydroxyprogesterone with a relative progestational activity of 1200 [11]. This drug is not approved in the United States by the Food and Drug Administration (FDA) but is widely prescribed in other countries. In France, its marketing authorization (MA) limits its indication to severe idiopathic hirsutism and polycystic ovary syndrome (PCOS) at a dose of $50 \mathrm{mg} /$ day, as well as for palliative treatment of prostatic adenocarcinoma or in the psychiatric population for sexually inappropriate behavior at a dose of 100 to $300 \mathrm{mg} /$ day. However, it is frequently prescribed outside the MA for contraceptive purposes or as a treatment for acne.

Early studies provided conflicting conclusions regarding oral contraceptive exposure on the risk of meningiomas [12-14]. In 2007, Gazzeri et al. reported the case of a 28-year-old transgender (male-to-female) patient treated with CPA for 5 years who developed a giant grade 1 meningothelial meningioma of the olfactory-groove [15], an observation later confirmed in a series of 12 patients [16]. Finally, a 2011 retrospective cohort showed an increased risk of meningiomas in patients exposed to high-dose CPA [17].

Recently, the European Medicines Agency (EMA) issued an alert on CPA based on the results of a cohort study from 2006 to 2015 that reported an increased risk of meningioma by 7 times after a 6-month exposure to CPA and by 20 times if the cumulative dose exceeded $60 \mathrm{~g}$.

Given this context and the knowledge that CPA prescription in France is particularly frequent $(89,000$ women had at least one prescription in 2017), we investigated the potential relationships between CPA exposure and meningiomas.

\section{Methods}

\section{Objectives}

This was a monocentric, epidemiological, retrospective study conducted at the Nantes University Hospital (CHU Nantes) and the ICO-René Gauducheau Cancer Center. Data were collected from medical records.

The main objective of this study was to determine the prevalence of CPA exposure in patients with one or more intracranial meningiomas treated surgically or by radiotherapy. The secondary objectives were to establish a description of patients with intracranial meningiomas and to determine whether there was a difference in patient characteristics and tumor characteristics of patients exposed to CPA compared with patients who had no hormonal exposure and patients who had been exposed to other hormones.

\section{Patients}

Patients eligible for inclusion were all those treated surgically for intracranial meningioma with anatomopathological confirmation at the Nantes University Hospital and all patients treated by conformal radiotherapy for meningioma at the ICO-René Gauducheau Cancer Center between January 1, 2014 and December 31, 2017.

Exclusion criteria were extracranial meningiomas and previously known risk factors for meningiomas: mutation in the NF2 gene and prior exposure (either accidental or therapeutic) to ionizing radiation.

\section{Data collected}

The local ethics committee (GNEDS: Groupe Nantais d'Ethique dans le Domaine de la Santé) approved the collection and use of this data (approval on November 12, 2018).

From medical reports of anesthesia, neurosurgery and/ or radiotherapy consultations, we collected the following data: age at diagnosis, sex (male, female, transgender), body mass index (BMI), circumstance of tumor discovery: incidental or symptomatic, number of meningiomas, evolution after the first treatment, type of radiotherapy (fractionated or radiosurgery), cumulative dose and number of sessions. For women, we also recorded: history of polycystic ovarian syndrome (PCOS), breast cancer, number of pregnancies, current or past use of CPA, tamoxifen, oral contraception, clomiphene or hormone replacement therapy for menopause. For men, we noted: history of breast cancer, prostate cancer, current or past use of CPA or androgen hormone replacement.

From the radiology reports, we collected the location of the tumor (supra or infratentorial) and the size. If the size was not described, we measured the lesion in its longest axis on preoperative or pre-radiotherapy $\mathrm{CT}$ scan or nuclear magnetic resonance imaging (MRI).

We evaluated the Simpson score from the neurosurgery report [18].

We collected tumor characteristics from the anatomopathological reports: WHO grade and the presence of hormone receptors (testosterone, progesterone, estradiol).

\section{Statistical analysis}

Numerical data were assembled and then analyzed with Microsoft Excel 2019 v.16.26. Statistical analyses were performed with GraphPad Prism 7 v7.0a software. 
Gender, history of hormonal treatment, SPOK, breast cancer, incidental or symptomatic finding, WHO grade, Simpson's score, presence of hormone receptors, type of conformational radiotherapy, tumor multiplicity and evolution were categorical variables. Age on diagnosis, BMI, number of pregnancies, tumor size, number of tumors, cumulative dose of conformal radiotherapy and number of sessions were continuous variables.

Results are presented as a mean with standard deviation or median for continuous variables and as a percentage for categorical variables.

The Mann-Whitney or Kruskal-Wallis tests were performed to compare the continuous variables. We performed the exact Fisher or Chi-square test for categorical data.

The significance threshold was set at 0.05 .

\section{Results}

\section{Patients included}

From a review of 469 records, we included 388 patients: 277 treated surgically and 111 treated with radiation therapy. 81 were not included because: 13 patients had previous radiation therapy, 1 patient had NF2, 25 patients had spinal meningiomas, 17 patients had no meningioma, 15 were duplicates and we did not include 10 patients due to lack of data.

The main characteristics are detailed in Table 1 . There were 292 women $(75.3 \%)$ and 96 men $(24.7 \%)$. Mean age on diagnosis was $60.7 \pm 13.1$ years. Mean BMI was $26.3 \pm 5.6 \mathrm{~kg} / \mathrm{m}^{2}$. The average number of pregnancies per woman was $2.41 \pm 1.7$. Diagnosis was symptomatic in $88.4 \%$ of the cases and the location was supratentorial in $86.6 \%$ of the cases. Mean tumor size was $3.85 \mathrm{~cm} \pm 1.66 \mathrm{~cm}$ in its longest axis. There were $6.8 \%$ of the patients with 2 or more meningiomas.

Among the patients treated surgically, the WHO grade was I for $81.8 \%$ and it was higher in $18.2 \%$ of the patients (Grades II and III). There were $89.5 \%$ of the patients with a Simpson score $<3$, it was $\geq 3$ in $10.5 \%$ of the cases (Simpson $3,4,5)$. For 73 patients, progesterone receptor expression was determined and was reported positive in $89 \%$ of the cases.

Among the patients treated by radiotherapy, 94 were treated by fractionated radiotherapy (average cumulative dose $53.2 \pm 4.5 \mathrm{~Gy}$ ) and 17 by radiosurgery. There were $27 \%$ of the patients operated before radiotherapy.

Of the 388 patients, $79.9 \%$ (310 patients) had no history of hormonal treatment. There were 78 patients $(21.1 \%)$ with a history of hormonal exposure. Among them, the prevalence of current or past exposure to CPA was 3.9\% (15 patients) and $16.2 \%$ (63 patients) were exposed to other hormonal treatment. Other hormonal treatment included: oral
Table 1 Characteristics of patients included in the study, values expressed as means with standard deviations or as an absolute value with percentage of the population

\begin{tabular}{|c|c|c|}
\hline Characteristics & Value & Number \\
\hline Age on diagnosis (y; mean and range) & $60.7(17-96)$ & 388 \\
\hline Sex ratio $(\mathrm{F} / \mathrm{M})$ & 292/96 & - \\
\hline Symptomatic discovery & $343(88.4 \%)$ & - \\
\hline Number of pregnancies & & 242 \\
\hline 0 & $34(14.0 \%)$ & - \\
\hline 1 to 3 & $165(68.2 \%)$ & - \\
\hline$>3$ & $43(17.8 \%)$ & - \\
\hline Multiple pregnancies & $4(1.8 \%)$ & - \\
\hline BMI $\left(\mathrm{kg} / \mathrm{m}^{2}\right)$ & $26.3 \pm 5.6$ & 382 \\
\hline$<18.5$ & $11(2.9 \%)$ & - \\
\hline $18.5-25$ & $147(38.5 \%)$ & - \\
\hline$>25$ & $224(58.6 \%)$ & - \\
\hline Location (supra/infra) & $336 / 52$ & - \\
\hline Multiple meningiomas ( 2 or more) & $25(6.4 \%)$ & 388 \\
\hline Longest diameter of tumor $(\mathrm{cm})$ & $4.4 \pm 5$ & 303 \\
\hline$<1 \mathrm{~cm}$ & $6(1.9 \%)$ & - \\
\hline 1 to $3 \mathrm{~cm}$ & $82(27.1 \%)$ & - \\
\hline 3 to $6 \mathrm{~cm}$ & $167(55.1 \%)$ & - \\
\hline 6 to $9 \mathrm{~cm}$ & $43(14.2 \%)$ & - \\
\hline$>9 \mathrm{~cm}$ & $5(1.7 \%)$ & - \\
\hline Simpson score & & 276 \\
\hline 1 & $99(35.9 \%)$ & - \\
\hline 2 & $148(53.6 \%)$ & - \\
\hline 3 & $13(4.7 \%)$ & - \\
\hline 4 & $16(5.8 \%)$ & - \\
\hline WHO grade & & 275 \\
\hline I & $225(81.8 \%)$ & - \\
\hline II & $48(17.5 \%)$ & - \\
\hline III & $2(0.7 \%)$ & - \\
\hline Progesterone receptor expression & $65(85.5 \%)$ & 73 \\
\hline
\end{tabular}

contraception for 30 patients (7.7\%), hormone replacement therapy for menopause for 21 patients $(5.4 \%)$, tamoxifen for 6 patients (1.5\%), clomiphene for 4 patients (1\%), and androgen replacement therapy for 2 patients $(0.5 \%)$. Of these patients, 7 patients $(1,8 \%)$ were exposed to nomegestrol acetate (NOMAC) and 2 patients $(0,2 \%)$ to chlormadinone acetate (CMA). Therefore, 24 patients $(6,2 \%)$ were exposed to synthetic progestogen $(\mathrm{SP}=\mathrm{CPA}+\mathrm{NOMAC}+\mathrm{CMA})$. The main characteristics of these patients are detailed in Supplementary Table 1.

\section{Patients exposed to CPA}

The main characteristics of the 15 patients exposed to CPA are detailed in Table 2. 13 patients were managed in emergency for neurological symptoms, 14 were surgically treated 
( 1 by radiosurgery), $26.7 \%$ of the patients had multiple meningiomas, 1 patient had 7 meningiomas (Fig. 1), and another had 4 meningiomas. The evolution after treatment was available for the 14 operated patients: 8 patients $(57.1 \%)$ were cured, 1 patient $(7.1 \%)$ had a decrease in tumor volume and 5 patients $(37.7 \%)$ were stabilized after the procedure. After neurosurgical management or radiation therapy, all patient under CPA had discontinued it.

The indication for CPA treatment was PCOS for 4 patients, contraceptive for 1 patient, alopecia for 1 patient, palliative treatment for prostate cancer for 1 patient and sexual conduct disorders for 1 patient. For the 7 other patients, the indication wasnot clearly identified. We were able to determine a cumulative dose of CPA for 6 patients: $325.5 \pm 11.7 \mathrm{~g}$ over a period of $17.8 \pm 6.4$ years.

\section{Patients with hormonal exposure}

Detailed characteristics of patients with other hormonal exposure excluding CPA are available in Table 2. There were 59 treated by surgery and 9 by fractional radiotherapy with a mean cumulative dose of $52.9 \pm 4.1 \mathrm{~Gy}$. We were able to determine tumor evolution during the follow-up for 57 patients: 41 patients $(71.9 \%)$ were cured, stabilization was obtained for 10 patients (17.5\%), reduction of tumor volume for 3 patients (5.3\%) and finally 3 patients (5.3\%) had tumor regrowth.

Detailed characteristics of patients with other hormonal exposure excluding SP are available in Supplementary Table 1.

\section{Patients without regained hormonal exposure}

Their characteristics are also detailed in Table 2. There were 210 patients treated surgically, 100 by radiotherapy,

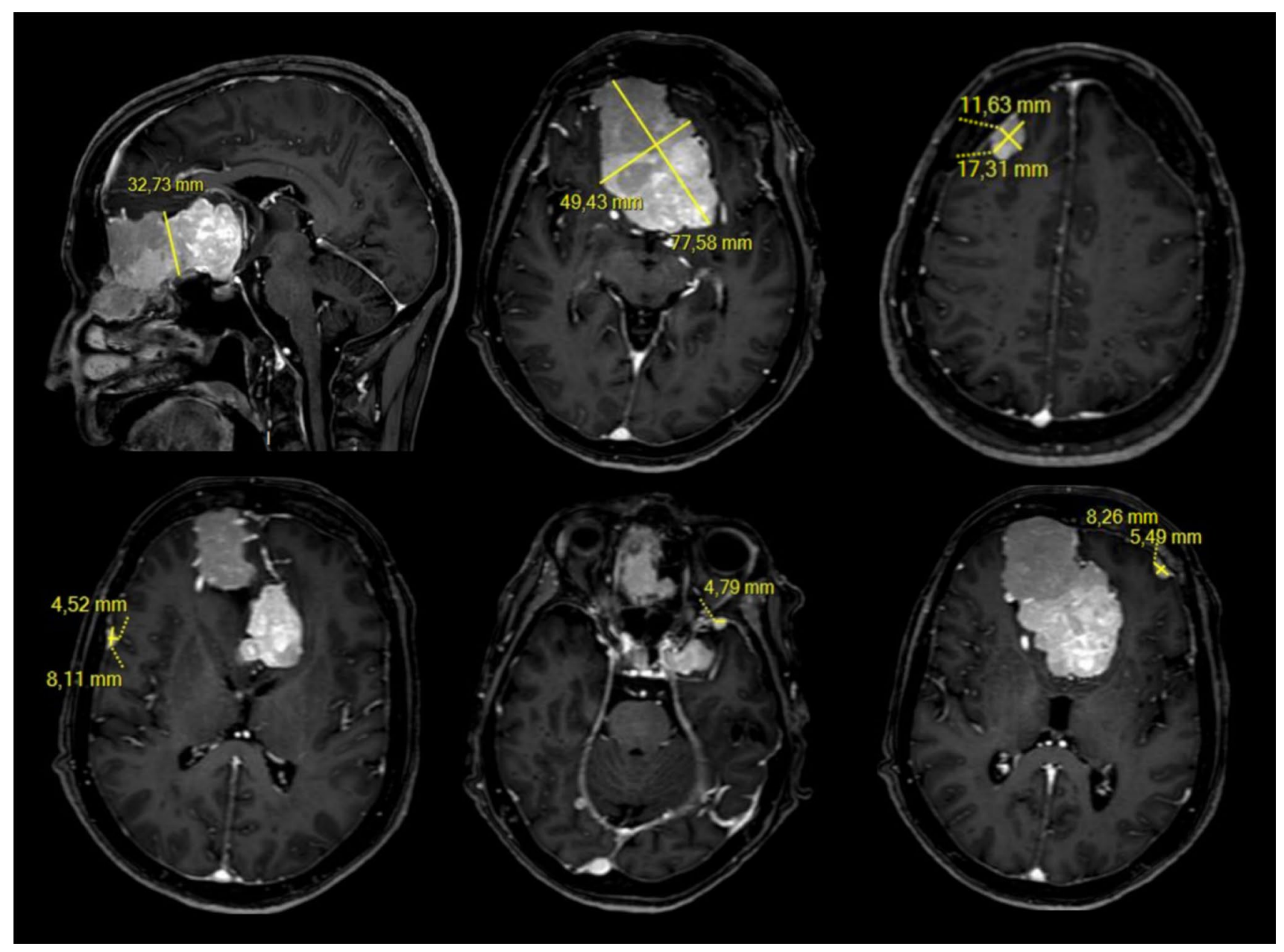

Fig. 1 MRI of a patient withpast use of CPA revealing 7 meningiomas 


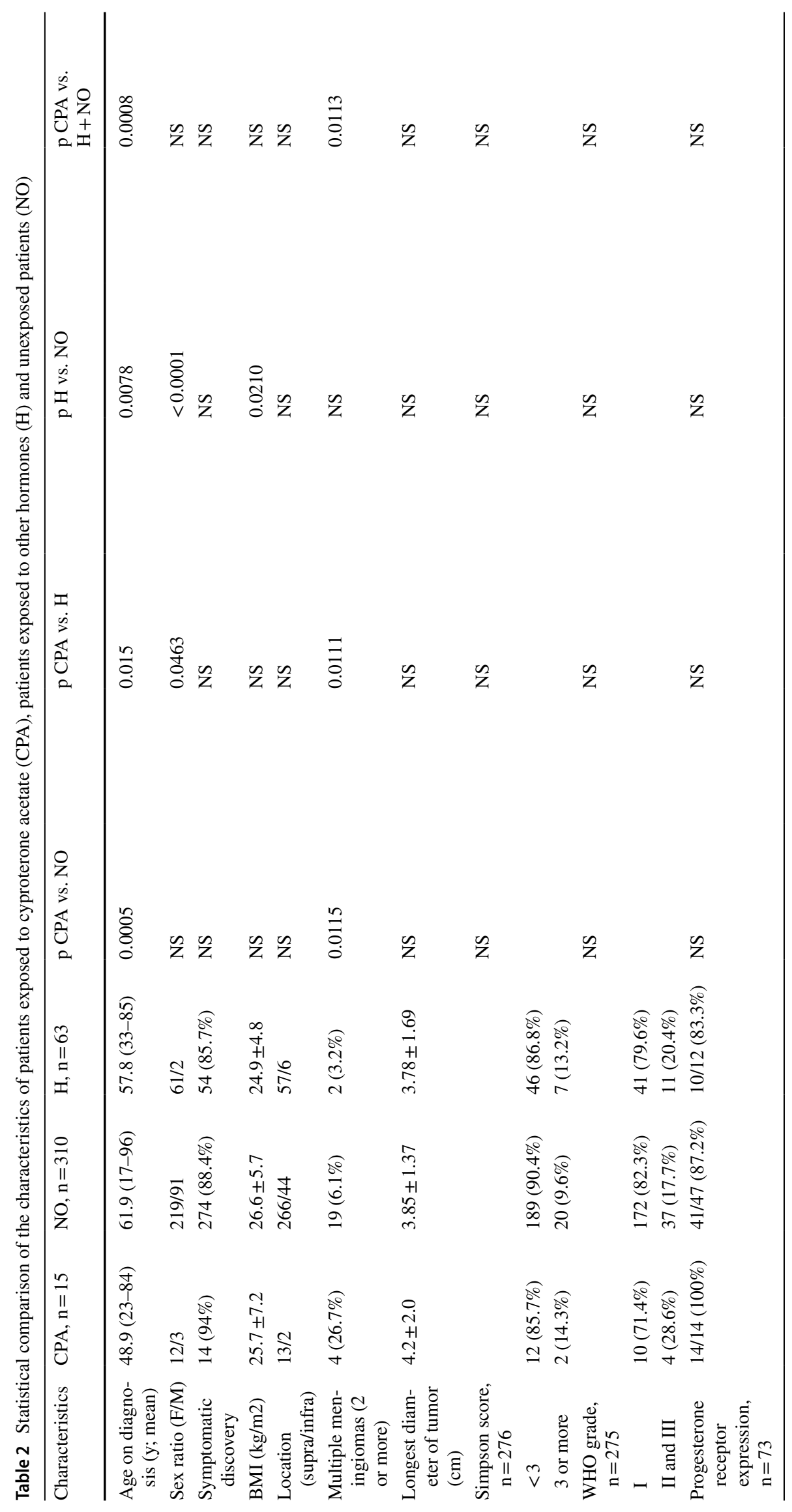


including 16 by radiosurgery. For the 84 patients treated by fractional radiotherapy, the mean cumulative dose was $53.3 \pm 4.6 \mathrm{~Gy}$. We were able to determine tumor evolution during the follow-up for 273 patients: 180 patients (65.9\%) were cured, stabilization was obtained for 61 patients (22.3\%), a reduction in tumor volume for 17 patients $(6.2 \%)$ and finally 15 patients (5.5\%) had tumor regrowth.

\section{Comparison of patient characteristics (Table 2)}

Compared with the unexposed group, patients who were exposed to CPA had meningiomas at a significantly younger age $(\mathrm{p}=0.0005)$ but also had more multiple meningiomas $(p=0.0115)$. Other characteristics were not significantly different.

When comparing the CPA-exposed group with the group of patients who had been exposed to other hormones CPA, the results were similar regarding the multiplicity of meningiomas $(\mathrm{p}=0.0111)$, age at onset of the tumor $(\mathrm{p}=0.015)$ and sex ratio $(\mathrm{p}=0.0463)$.

We compared patients who were exposed to CPA with all other patients. We found similar results with a significant difference in terms of multiplicity of meningiomas $(p=0.0113)$ as well as younger age at onset $(p=0.0008)$.

When comparing the SP-exposed group to the unexposed group (Supplementary Table 1), the group of patients who had been exposed to other hormones excluding SP and with all other patients, the results were similar to the CPA comparison excepted for the sex ratio when comparing the SPexposed group to the other hormones group $(\mathrm{p}=0.1164)$.

\section{Discussion}

This study is the first to establish the prevalence of hormone therapy, in particular CPA, in a comprehensive, monocentric cohort of patients treated for one or more meningiomas. This prevalence was $3.9 \%$ for CPA and $16.2 \%$ for other hormonal treatment.

Since numerous publications have reported cases of meningiomas in patients treated with CPA since 2007 [ 15 , 19-23], our practitioners therefore systematically questioned patients about their current or past use of one or more hormonal treatments.

Our results are consistent with the literature, finding $26.7 \%$ of multiple meningiomas on CPA versus $5.6 \%$ in patients not exposed to CPA. We observed that a majority of meningiomas occurring under CPA were located at the anterior level of the base of the skull (75\%), in accordance with the literature $[24,25]$. The embryology of meninges differs between convexity (neural crests) and the base of the skull (mesoderm) [26]. Thus, we could consider an increased susceptibility of the meninges of the base of the skull to progestative. Moreover, a specific mutational landscape would dominate in this location of basal meningiomas: $49 \%$ of mutations in the NF2 gene, $24 \%$ in the AKT1/TRAF7, KLF4/TRAF7, SMO, PIK3CA, or POLR4 genes, and $47 \%$ without any mutation $[24,26]$. In $35 \%$ of the cases, two particular mutations acting synergistically with the SMO mutation in anterior stage meningiomas appear to increase meningeal sensitivity to progesterone analogues: PIK3CA and TRAF7 (mutually exclusive). The common denominator of the latter two may be the altered activity of prostaglandin-D2-synthase (PGDS), which is specific to meningiomatous progenitors [27].

The preferential location and different meningeal hormone sensitivity therefore raise the hypothesis of the existence of two types of meningiomas regardless of their size:

- Neo-meningiomas under CPA more readily at the base of the skull.

- Pre-existing meningiomas growing under CPA treatment at the convexity.

Regression or stabilization of meningiomas after CPA discontinuation has been reported by several teams $[16,17$, $19,28]$. In the present study, a female patient with 4 meningiomas under CPA on diagnosis stopped treatment after surgery for the largest, symptomatic meningioma leading to a stabilization of the 3 others. This phenomenon is one more argument in favor of the relationship between CPA and meningiomas. Kalamarides et al. observed a decrease in spontaneous vascularization observed on MRI after discontinuation of CPA. An analogy between CPA, luteal phase and pregnancy through hemodynamic changes could therefore explain that the cessation of CPA may influence the regression in size of meningiomas. These changes oppose the hypothesis of accelerated cell growth in other hormonedependent tumors in which progesterone has a mitogenic role (breast cancer) [29].

Owing to the inclusion of only treated meningiomas, symptomatic meningiomas are overrepresented $(88.4 \%)$ versus the usual $70 \%$ of diagnosed meningiomas [30]. No studies have demonstrated a mitogenic effect of CPA on arachnoid cells. Our results also show no difference in size $(p=0.6718)$. As a result, the hypothesis that we favor is an increase in volume growth kinetics leading to symptomatology by angiogenic effect rather than by mitogenicity.

In addition to CPA, we studied hormonal exposures such as menopausal hormone replacement therapy, tamoxifen, clomiphene, oral contraceptive and androgen substitution. We found no difference in either the size or number of meningiomas compared with other patients. Studies concerning other hormonal treatment are contradictory with neutral, promoting or even protective effect concerning menopausal 
hormone replacement therapy [12-14, 31-34], oral contraceptives or medically-assisted reproduction treatment [35]. Establishing a link between hormone treatment (excluding CPA) and the risk of meningiomas therefore remains difficult. Recently, a case series of meningiomas in patients treated with another hormonal therapy has come to our attention: Passeri et al. found three cases of meningiomas in patients treated with NOMAC with tumor reduction following discontinuation of treatment [25]. NOMAC shares several biological effects with CPA as an anti-androgenic and progestative agonist. In addition, authors are currently interested in another progesterone analogue, CMA and its potential association with meningiomas [36, 37].

These observations reinforce the idea that meningiomas and their growth are not only related to a specific effect of CPA but to a specific effect mediated by the progesterone receptor. There is therefore a need for larger studies on the specific link between progesterone analogues and meningiomas. In our study, 7 patients were exposed to NOMAC, 6 were treated surgically, 1 were treated with radiotherapy, and only 1 had multiple meningiomas ( 3 meningiomas), and 2 patients were exposed to CMA, 1 was treated surgically and 1 by radiotherapy. None had multiple meningioma.

The main limitation of our study is its retrospective design. We were unable to collect data on untreated meningiomas under active surveillance owing to the lack of a follow-up registry. Nevertheless, as a University Hospital, we were comprehensive about the population pool of our region and exposure to hormone therapy was systematically collected in the records because practitioners were well aware of this debate.

In conclusion, the iatrogeny potentially engendered by CPA is a major public health issue. Recommendations for good practice have been issued concerning the use of CPA. We are convinced that this broad information will strongly decrease the prescription of CPA in the coming years and thus the prevalence of meningiomas under CPA. Apart from its MA, the prescription of CPA is prohibited.

Consideration of the impact of CPA should also be nuanced depending on the doses received by the patient since the threshold for a significant increase in the risk of developing a meningioma has been set at $60 \mathrm{~g}$ in cumulative dose or 6 months at a high dose [38].

Research on this subject will have to be proportional since the number of meningiomas diagnosed in the context of CPA will tend to decrease significantly. Our present data suggest that research on this subject should more broadly concern all synthetic progestogen, especially NOMAC and CMA.

Acknowledgements We thank Mr Peter Tucker for English language editing.
Author contributions ES and AL: collected the data, contributed in data analysis and interpretation and drafted the manuscript. AL, AA, ES and SH performed statistical analysis. DL performed the pathological analysis. FT contributed in data collection. DD and VR conceived and designed the analysis. All authors performed a critical revision of the manuscript and significantly contributed to the final version. All authors approved the final manuscript.

\section{Compliance with ethical standards}

Conflict of interest The authors declare that they have no conflict of interest.

Ethical approval The local ethicscommittee (GNEDS: Groupe Nantais d'Ethique dans le Domaine de la Santé)approved the collection and use of this data (approval on November 12,2018).

\section{References}

1. Marosi C, Hassler M, Roessler K, Reni M, Sant M, Mazza E et al (2008) Meningioma. Crit Rev Oncol Hematol 67:153-171. https ://doi.org/10.1016/j.critrevonc.2008.01.010

2. Wiemels J, Wrensch M, Claus EB (2010) Epidemiology and etiology of meningioma. J Neurooncol 99:307-314. https://doi. org/10.1007/s11060-010-0386-3

3. Ostrom QT, Gittleman H, Fulop J, Liu M, Blanda R, Kromer C et al (2015) CBTRUS statistical report: primary brain and central nervous system tumors diagnosed in the United States in 20082012. Neuro-Oncol 17(Suppl 4):iv1-i62. https://doi.org/10.1093/ neuonc/nov189

4. Cea-Soriano L, Wallander M-A, García Rodríguez LA (2012) Epidemiology of meningioma in the United Kingdom. Neuroepidemiology 39:27-34. https://doi.org/10.1159/000338081

5. Zouaoui S, Darlix A, Rigau V, Mathieu-Daudé H, Bauchet F, Bessaoud F et al (2018) Descriptive epidemiology of 13,038 newly diagnosed and histologically confirmed meningiomas in France: 2006-2010. Neurochirurgie 64:15-21. https://doi. org/10.1016/j.neuchi.2014.11.013

6. Yamanaka R, Hayano A, Kanayama T (2017) Radiation-induced meningiomas: an exhaustive review of the literature. World Neurosurg 97:635-644

7. Yonehara S, Brenner AV, Kishikawa M, Inskip PD, Preston DL, Ron E et al (2004) Clinical and epidemiologic characteristics of first primary tumors of the central nervous system and related organs among atomic bomb survivors in Hiroshima and Nagasaki, 1958-1995. Cancer 101:1644-1654. https://doi.org/10.1002/ cncr.20543

8. Kotecha RS, Pascoe EM, Rushing EJ, Rorke-Adams LB, Zwerdling T, Gao X et al (2011) Meningiomas in children and adolescents: a meta-analysis of individual patient data. Lancet Oncol 12:1229-1239. https://doi.org/10.1016/S1470 $-2045(11) 70275-3$

9. Baldi I, Engelhardt J, Bonnet C, Bauchet L, Berteaud E, Grüber A et al (2018) Epidemiology of meningiomas. Neurochirurgie 64:514. https://doi.org/10.1016/j.neuchi.2014.05.006

10. Carroll RS, Glowacka D, Dashner K, Black PM (1993) Progesterone receptor expression in meningiomas. Cancer Res 53:1312-1316

11. Neumann F (2009) The antiandrogen cyproterone acetate: discovery, chemistry, basic pharmacology, clinical use and tool in basic research. Exp Clin Endocrinol Diabetes 102:1-32. https://doi. org/10.1055/s-0029-1211261 
12. Custer B, Longstreth W, Phillips LE, Koepsell TD, Van Belle G (2006) Hormonal exposures and the risk of intracranial meningioma in women: a population-based case-control study. BMC Cancer 6:152. https://doi.org/10.1186/1471-2407-6-152

13. Lee E, Grutsch J, Persky V, Glick R, Mendes J, Davis F (2006) Association of meningioma with reproductive factors. Int J Cancer 119:1152-1157. https://doi.org/10.1002/ijc.21950

14. Claus EB, Calvocoressi L, Bondy ML, Wrensch M, Wiemels JL, Schildkraut JM (2013) Exogenous hormone use, reproductive factors, and risk of intracranial meningioma in females: Clinical article. J Neurosurg 118:649-656. https://doi.org/10.3171/2012.9.JNS12811

15. Gazzeri R, Galarza M, Gazzeri G (2007) Growth of a meningioma in a transsexual patient after estrogen-progestin therapy. N Engl J Med 357:2411-2412. https://doi.org/10.1056/NEJMc071938

16. Bernat AL, Oyama K, Hamdi S, Mandonnet E, Vexiau D, Pocard $M$ et al (2015) Growth stabilization and regression of meningiomas after discontinuation of cyproterone acetate: a case series of 12 patients. Acta Neurochir (Wien) 157:1741-1746. https://doi. org/10.1007/s00701-015-2532-3

17. Gil M, Oliva B, Timoner J, Maciá MA, Bryant V, de Abajo FJ (2011) Risk of meningioma among users of high doses of cyproterone acetate as compared with the general population: evidence from a population-based cohort study. Br J Clin Pharmacol 72:965-968. https://doi.org/10.1111/j.1365-2125.2011.04031.x

18. SIMPSON D (1957) The recurrence of intracranial meningiomas after surgical treatment. J Neurol Neurosurg Psychiatry 20:22-39. https://doi.org/10.1136/jnnp.20.1.22

19. Cebula H, Pham TQ, Boyer P, Froelich S (2010) Regression of meningiomas after discontinuation of cyproterone acetate in a transsexual patient. Acta Neurochir (Wien) 152:1955-1956. https://doi. org/10.1007/s00701-010-0787-2

20. ter Wengel PV, Martin E, Gooren L, Den Heijer M, Peerdeman SM (2016) Meningiomas in three male-to-female transgender subjects using oestrogens/progestogens and review of the literature. Andrologia 48(10):1130-1137. https://doi.org/10.1111/and.12550

21. Mancini I, Rotilio A, Coati I, Seracchioli R, Martelli V, Meriggiola MC (2018) Presentation of a meningioma in a transwoman after nine years of cyproterone acetate and estradiol intake: case report and literature review. Gynecol Endocrinol Off J Int Soc Gynecol Endocrinol 34:456-459. https://doi.org/10.4103/sni.sni_22_18

22. Bergoglio MT, Gómez-Balaguer M, Almonacid Folch E, Hurtado Murillo F, Hernández-Mijares A (2013) Symptomatic meningioma induce by cross-sex hormone treatment in a male-to-female transsexual. Endocrinol Nutr 60:264-267. https://doi.org/10.1016/j. endonu.2012.07.004

23. Anda T, Honda M, Ishihara T, Kamei T (2014) Progression of intracranial meningioma during luteinizing hormone-releasing hormone agonist treatment for prostate cancer: case report. Neurol Med Chir (Tokyo) 54:327-330. https://doi.org/10.2176/nmc.cr2012-0417

24. Boetto J, Apra C, Bielle F, Peyre M, Kalamarides M (2018) Selective vulnerability of the primitive meningeal layer to prenatal Smo activation for skull base meningothelial meningioma formation. Oncogene 37:4955-4963. https://doi.org/10.1038/s41388-018-0328-7

25. Passeri T, Champagne P-O, Bernat A-L, Hanakita S, Salle H, Mandonnet $\mathrm{E}$ et al (2019) Spontaneous regression of meningiomas after interruption of nomegestrol acetate: a series of three patients. Acta Neurochir (Wien) 61:761-765. https://doi.org/10.1007/s00701-01903848-x

26. Peyre M, Gaillard S, de Marcellus C, Giry M, Bielle F, Villa C et al (2018) Progestin-associated shift of meningioma mutational landscape. Ann Oncol 29:681-686. https://doi.org/10.1093/annon $\mathrm{c} / \mathrm{mdx} 763$

27. Peyre M, Salaud C, Clermont-Taranchon E, Niwa-Kawakita M, Goutagny S, Mawrin C et al (2015) PDGF activation in PGDSpositive arachnoid cells induces meningioma formation in mice promoting tumor progression in combination with Nf2 and Cdkn2ab loss. Oncotarget 6:32713-32722. https://doi.org/10.18632/oncot arget.5296

28. Shimizu J, Matsumoto M, Yamazaki E, Yasue M (2008) Spontaneous regression of an asymptomatic meningioma associated with discontinuation of progesterone agonist administration. Neurol Med Chir (Tokyo) 48:227-230. https://doi.org/10.2176/nmc.48.227

29. Kalamarides M, Peyre M (2017) Dramatic shrinkage with reduced vascularization of large meningiomas after cessation of progestin treatment. World Neurosurg 101:814.e7-814.e10. https://doi. org/10.1016/j.wneu.2017.03.013

30. Islim AI, Mohan M, Moon RDC, Srikandarajah N, Mills SJ, Brodbelt AR et al (2019) Incidental intracranial meningiomas: a systematic review and meta-analysis of prognostic factors and outcomes. J Neurooncol 142:211-221. https://doi.org/10.1007/s11060-01903104-3

31. Hatch EE, Linet MS, Zhang J, Fine HA, Shapiro WR, Selker RG et al (2005) Reproductive and hormonal factors and risk of brain tumors in adult females. Int J Cancer 114:797-805. https://doi. org/10.1002/ijc.20776

32. Jhawar BS, Fuchs CS, Colditz GA, Stampfer MJ (2003) Sex steroid hormone exposures and risk for meningioma. J Neurosurg 99:848853. https://doi.org/10.3171/jns.2003.99.5.0848

33. Wigertz A, Lönn S, Mathiesen T, Ahlbom A, Hall P, Feychting M et al (2006) Risk of brain tumors associated with exposure to exogenous female sex hormones. Am J Epidemiol 164:629-636. https:// doi.org/10.1093/aje/kwj254

34. Blitshteyn S, Crook JE, Jaeckle KA (2008) Is there an association between meningioma and hormone replacement therapy? J Clin Oncol Off J Am Soc Clin Oncol 26:279-282. https://doi. org/10.1200/JCO.2007.14.2133

35. Shahin MN, Magill ST, Dalle Ore CL, Viner JA, Peters PN, Solomon DA et al (2019) Fertility treatment is associated with multiple meningiomas and younger age at diagnosis. J Neurooncol 143:137144. https://doi.org/10.1007/s11060-019-03147-6

36. Roux A, Tauziede-Espariat A, Zanello M, Gareton A, Malaize H, Benzakoun J, Zah-Bi G, Oppenheim C, Plu-Bureau G, Chretien F, Pallud J (2020) Symptomatic progestin-associated atypical grade II meningioma. A first case report. Neurochirurgie 66:174-178. https ://doi.org/10.1016/j.neuchi.2019.12.013

37. Apra C, Roblot P, Alkhayri A, Le Guérinel C, Polivka M, Chauvet D (2020) Female gender and exogenous progesterone exposition as risk factors for spheno-orbital meningiomas. J Neurooncol 149:95101. https://doi.org/10.1007/s11060-020-03576-8

38. Weill A, Cadier B, Nguyen P, Coste J (2019) Exposition à de fortes doses d'acétate de cyprotérone. Amélie Santé. https://www.ameli .fr/l-assurance-maladie/statistiques-et-publications/etudes-en-sante -publique/etudes-pharmaco-epidemiologiques/acetate-de-cyproteron e-et-risque-de-meningiome.php

Publisher's Note Springer Nature remains neutral with regard to jurisdictional claims in published maps and institutional affiliations. 


\section{Affiliations}

Edouard Samarut $^{1} \cdot$ Alexandre Lugat $^{2,3}$ (10) Aymeric Amelot ${ }^{4,5} \cdot$ Emeric Scharbarg $^{2} \cdot$ Samy Hadjadj $^{2} \cdot$ Claire Primot $^{6}$. Delphine Loussouarn ${ }^{7} \cdot$ François Thillays $^{8} \cdot$ Kevin Buffenoir $^{1} \cdot$ Bertrand Cariou $^{2} \cdot$ Delphine Drui $^{2} \cdot$ Vincent Roualdes $^{1}$

1 Neurotraumatology, Neurosurgery Department, Hotel-Dieu, CHU Nantes, Nantes, France

2 L'institut du thorax, Endocrinology, Diabetology and Nutrition Department, CHU Nantes, Nantes, France

3 Inserm UMR 1232, CRCINA, Université d'Angers, Université de Nantes, Nantes, France

4 Neurosurgery Department, Bretonneau Hospital, CHRU Tours, Tours, France

5 Inserm UMR 1253, Université de Tours, Tours, France
6 Inserm UMR 1413, CIC, Endocrinology, Diabetology and Nutrition, CHU Nantes, Nantes, France

7 Pathology Department, Hotel-Dieu, CHU Nantes, Nantes, France

8 Radiotherapy Department, Institut de Cancérologie de l'Ouest (ICO), Saint-Herblain, France 


\section{Terms and Conditions}

Springer Nature journal content, brought to you courtesy of Springer Nature Customer Service Center GmbH ("Springer Nature").

Springer Nature supports a reasonable amount of sharing of research papers by authors, subscribers and authorised users ("Users"), for smallscale personal, non-commercial use provided that all copyright, trade and service marks and other proprietary notices are maintained. By accessing, sharing, receiving or otherwise using the Springer Nature journal content you agree to these terms of use ("Terms"). For these purposes, Springer Nature considers academic use (by researchers and students) to be non-commercial.

These Terms are supplementary and will apply in addition to any applicable website terms and conditions, a relevant site licence or a personal subscription. These Terms will prevail over any conflict or ambiguity with regards to the relevant terms, a site licence or a personal subscription (to the extent of the conflict or ambiguity only). For Creative Commons-licensed articles, the terms of the Creative Commons license used will apply.

We collect and use personal data to provide access to the Springer Nature journal content. We may also use these personal data internally within ResearchGate and Springer Nature and as agreed share it, in an anonymised way, for purposes of tracking, analysis and reporting. We will not otherwise disclose your personal data outside the ResearchGate or the Springer Nature group of companies unless we have your permission as detailed in the Privacy Policy.

While Users may use the Springer Nature journal content for small scale, personal non-commercial use, it is important to note that Users may not:

1. use such content for the purpose of providing other users with access on a regular or large scale basis or as a means to circumvent access control;

2. use such content where to do so would be considered a criminal or statutory offence in any jurisdiction, or gives rise to civil liability, or is otherwise unlawful;

3. falsely or misleadingly imply or suggest endorsement, approval, sponsorship, or association unless explicitly agreed to by Springer Nature in writing;

4. use bots or other automated methods to access the content or redirect messages

5. override any security feature or exclusionary protocol; or

6. share the content in order to create substitute for Springer Nature products or services or a systematic database of Springer Nature journal content.

In line with the restriction against commercial use, Springer Nature does not permit the creation of a product or service that creates revenue, royalties, rent or income from our content or its inclusion as part of a paid for service or for other commercial gain. Springer Nature journal content cannot be used for inter-library loans and librarians may not upload Springer Nature journal content on a large scale into their, or any other, institutional repository.

These terms of use are reviewed regularly and may be amended at any time. Springer Nature is not obligated to publish any information or content on this website and may remove it or features or functionality at our sole discretion, at any time with or without notice. Springer Nature may revoke this licence to you at any time and remove access to any copies of the Springer Nature journal content which have been saved.

To the fullest extent permitted by law, Springer Nature makes no warranties, representations or guarantees to Users, either express or implied with respect to the Springer nature journal content and all parties disclaim and waive any implied warranties or warranties imposed by law, including merchantability or fitness for any particular purpose.

Please note that these rights do not automatically extend to content, data or other material published by Springer Nature that may be licensed from third parties.

If you would like to use or distribute our Springer Nature journal content to a wider audience or on a regular basis or in any other manner not expressly permitted by these Terms, please contact Springer Nature at

onlineservice@springernature.com 